\title{
Co-adaptation of Escherichia coli and Coliphage $\lambda$ vir in Continuous Culture
}

\author{
By E. SPANAKIS $†$ AND M. T. HORNE* \\ Aquatic Biotechnology, Institute of Aquaculture, University of Stirling, Stirling FK9 4LA,UK
}

(Received 1 April 1986; revised 18 July 1986)

\begin{abstract}
Populations of the bacterium Escherichia coli and of its phage $\lambda$ vir appeared to equilibrate in continuous cultures. The bacterial end-populations were heterogeneous in respect of their resistance to $\lambda$ vir and their ability to utilize maltose. The most competitive of the selected bacteria were mutants which had a reduced rate of synthesis of $\lambda$-receptor so as to become highly, but not totally, resistant to the phage. The coexisting phage had an increased affinity for the receptor and an altered antigenic specificity, suggesting adaptation of its adsorption site in response to the evolution of resistance in the bacteria.
\end{abstract}

\section{INTRODUCTION}

Mixed continuous cultures of lytic bacteriophages (phages) and their host bacteria have served as model systems for studying how organisms coexist in nature. These systems may also provide useful experimental data for the study of predator-prey theory in general (Campbell, 1961). Paynter \& Bungay (1969, 1971), Horne (1970a,b), Levin et al. (1977) and Chao et al. (1977), working with Escherichia coli and phages of the T series, and Cowlishaw \& Mrsa (1975), Cannon et al. (1976) and Barnet et al. (1981), using cyanobacteria and cyanophages, have all shown that hosts and phages may persist indefinitely in continuous cultures despite the fact that shortly after the addition of phage the overall bacterial population becomes highly resistant to it. To explain the way in which the populations of host, resistant bacteria and phage equilibrate in a continuous culture, Levin and his colleagues (Levin et al., 1977; Chao et al., 1977) proposed a density-dependent feedback mechanism based on the assumptions (i) that the susceptible bacteria are fitter in competition with the resistant ones by having a higher intrinsic rate of increase, and (ii) that phage-host encounters and predation do not occur when the populations are below a certain density. Alternatively, it has been argued that the phage does not rest its persistence upon the fate of its original hosts but mutates continuously to find new hosts among the resistant bacteria (Horne, 1970a,b; Chao et al., 1977; Barnet et al., 1981).

Due to the lack of a sensitive technique for isolating susceptible variants from phage-resistant populations the existing evidence in support of the above hypotheses is small and circumstantial. This problem was overcome here by using continuous cultures of $E$. coli and a mutant of coliphage $\lambda$ whose intracellular development is exclusively lytic ( $\lambda$ vir; Jacob \& Wollman, 1954). Adsorption of $\lambda$ onto an $E$. coli cell is prevented by mutations which inhibit the synthesis or distort the stereochemical conformation of the phage-receptor protein ( $\lambda$-receptor). Most of the mutations which inhibit the synthesis of $\lambda$-receptor, pleiotropically affect the ability of the cell to utilize maltose (Thirion \& Hofnung, 1972). It was, therefore, anticipated that the phage would grow on maltose-utilizing bacteria which could be detected on selective media. The isolation of novel host-genotypes with intermediate degrees of resistance reported here provides a new insight into the mechanisms of phage-host coexistence.

† Present address: Department of Biology, University of Crete, GR 71100, Heraklion, Greece. 


\section{METHODS}

Strains. A single colony of E. coli C600 (Appleyard, 1954) and a single plaque from a $\lambda$ vir lysate were used to provide the stock host and phage which are referred to below as original organisms. These strains and $E$. coli strain $\mathrm{K} 12(\lambda)$ were provided by Professor D. Ritchie (Liverpool University, UK).

Media and chemicals. 'Lambda broth' (LB) (Davison \& Freifelder, 1966), with Tryptone (Oxoid, L42) reduced to $0.5 \%(\mathrm{w} / \mathrm{v})$ to avoid foaming, was used in liquid cultures or supplemented with $0.7 \%(\mathrm{w} / \mathrm{v})$ Agar no. 1 (Oxoid, L11) for plating (LA). LA, supplemented with $500 \mu \mathrm{g}$ streptomycin sulphate (Sigma) $\mathrm{ml}^{-1}$, was used for counting free phage as described below. The media EMBmalI ( $\mathrm{pH} \mathrm{7.6)}$ and EMBmallI (pH 6.8) were the same as Eosin Methylene Blue Agar (Oxoid, CM69) except that lactose was replaced by maltose, and in EMBmallI $\mathrm{K}_{2} \mathrm{HPO}_{4}$ was replaced by $\mathrm{KH}_{2} \mathrm{PO}_{4}$. On these media colonies which produce acid by catabolizing the available sugar appear black by transmitted light and exhibit a greenish metallic sheen by reflected light; colonies which are unable to utilize the sugar are colourless. Many intermediate strains fail to lower the $\mathrm{pH}$ of EMBmalI sufficiently to develop colour. These are distinguished by producing colour only on EMBmallI. Unless otherwise indicated chemicals were obtained from $\mathrm{BDH}$ at the purest grades available.

Chemostats. Cultures ( $300 \mathrm{ml}, \mathrm{LB})$ were grown in $500 \mathrm{ml}$ capacity vessels at $37^{\circ} \mathrm{C}$. The $\mathrm{pH}$ of the cultures was $6 \cdot 8 \pm 0 \cdot 2$. Aeration and stirring were achieved with humidified sterile air $\left(11 \mathrm{~min}^{-1}\right)$ which maintained a small positive pressure within the vessel. Sterile medium was added by peristalsis at a dilution rate $(D)$ of $0.04 \mathrm{~h}^{-1}$, at which a steady-state bacterial population doubles every $17.3 \mathrm{~h}$. Inoculation was by injection through a rubber seal and samples were collected from a special port at the outflow tube.

Identification of bacterial and phage strains. The presence of the $\mathrm{Lac}^{-}$marker (inability to utilize lactose) of $E$. coli C600 was identified on EMB medium. The phage was identified by its ability to form plaques on strain $\mathrm{K} 12(\lambda)$ and its failure to grow on a spontaneous mutant of the original bacterial strain resistant to $\lambda$ and unable to utilize maltose (strain C600mal/ $\lambda$ ).

Preparation of cell-free suspensions. Chemostat samples were passed through Millipore GSWP filter discs (exclusion limits $0.22 \mu \mathrm{m}$ ) and the filtrates were stored at $4{ }^{\circ} \mathrm{C}$. Their phage titre was determined before use.

Determination of numbers of bacteria and phage. This was done by colony and plaque counting using the following one-layer technique. Samples of serially diluted suspensions of the organisms were mixed with molten LA (at $46{ }^{\circ} \mathrm{C}$ ) and plated. The omission of a bottom agar layer did not affect the counts and was preferred to the usual, overlay technique for simplicity and economy. Appropriate indicator bacteria $\left(10^{8}\right.$ cells $\left.\mathrm{ml}^{-1}\right)$ or phage lysate (for counting resistant bacteria; $10^{8}$ p.f.u. $\mathrm{ml}^{-1}$ ) were added to the medium just before plating. To determine numbers of free phage particles in bacterial-phage mixtures, these were plated with streptomycin sulphate using a streptomycin-resistant mutant (strain C600str) of the original bacterium as an indicator. The drug inhibits phageprotein synthesis in infected streptomycin-sensitive cells which, therefore, do not form plaques (Symonds, 1957). For counting total p.f.u. the antibiotic was omitted.

Bacterial susceptibility to a phage. This was quantified by measuring the relative efficiency of plating (REP) of the phage on lawns of the isolate. The REP is the ratio of the number of plaques formed on an isolate to the number formed on the original strain. Synthesis of $\lambda$-receptor was induced (Schwartz, 1976) by adding maltose $0 \cdot 5 \%$ (w/v) and $\mathrm{KH}_{2} \mathrm{PO}_{4} 0 \cdot 2 \%(\mathrm{w} / \mathrm{v})$ to the growth medium.

Determination of the bacterial Mal character. Samples of serially diluted bacterial suspensions were spread on the surface of EMBmalI and II media. Single colonies with the various phenotypes were subcultured and re-identified on both media. They were then stored in LB at $4{ }^{\circ} \mathrm{C}$ for further tests.

Determination of the phage-antiserum reaction constant. $\lambda v i r$-specific antiserum was raised in a rabbit as described by Barnet et al. (1981). For determining the phage-inactivation constant (Adams, 1959) the kinetics of the phageserum reaction were followed in three reaction-tubes by counting residual, active phage at $5 \mathrm{~s}$ intervals over a period of $50 \mathrm{~s}$.

Determination of adsorption rates. Phage were added to batch cultures of streptomycin-sensitive bacteria $\left(5 \times 10^{8}\right.$ cells $\left.\mathrm{ml}^{-1}\right)$ at a multiplicity of infection of 0.01 . Numbers of adsorbed phage were determined by subtraction of the residual free phage count (estimated using streptomycin as described above) from the total p.f.u. Any significant drop of the total p.f.u. counts with time was interpreted as non-productive adsorption; in such cases, the rates of total and non-productive adsorption were determined by subtracting the total p.f.u. and the residual free phage, respectively, from the number of phage particles added to the adsorption tube. For determining the adsorption-reaction constant (Schlesinger, 1932) the reaction was followed over a $15 \mathrm{~min}$ period in five replicate adsorption tubes.

Determination of bacterial intrinsic mean generation time. Exponentially growing bacteria were diluted in prewarmed $\left(37^{\circ} \mathrm{C}\right) \mathrm{LB}$ to a density of approximately $10^{4}$ cells $\mathrm{ml}^{-1}$ and their numbers determined every $30 \mathrm{~min}$ for $5 \mathrm{~h}$ by viable plate counting. The mean generation time was estimated as the reciprocal of $k$ in the equation

$$
\log _{2}\left(N_{\mathrm{t}} / N_{0}\right)=k t
$$

where $N_{0}$ and $N_{1}$ are the numbers of viable cells at time zero and time $t$. 


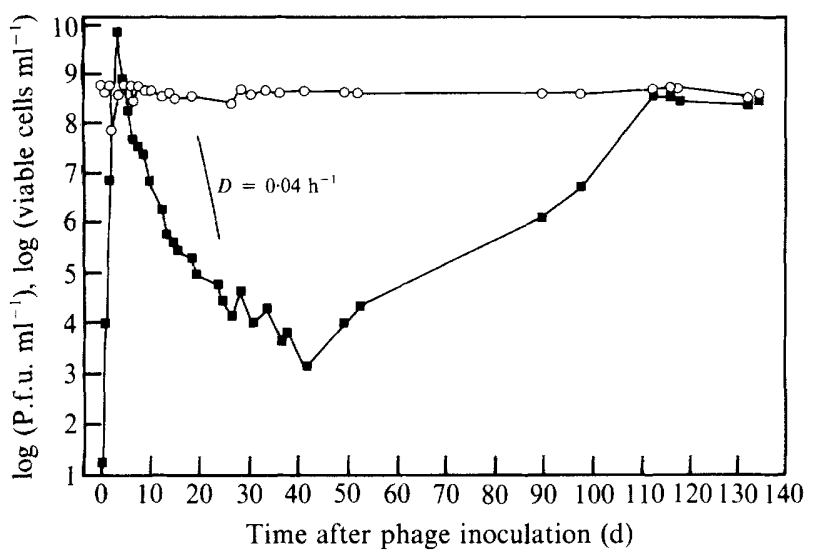

Fig. 1. Population dynamics in culture 1 . $\bigcirc$, Bacterial counts; $\boldsymbol{\square}$, phage counts; $D$, dilution rate.

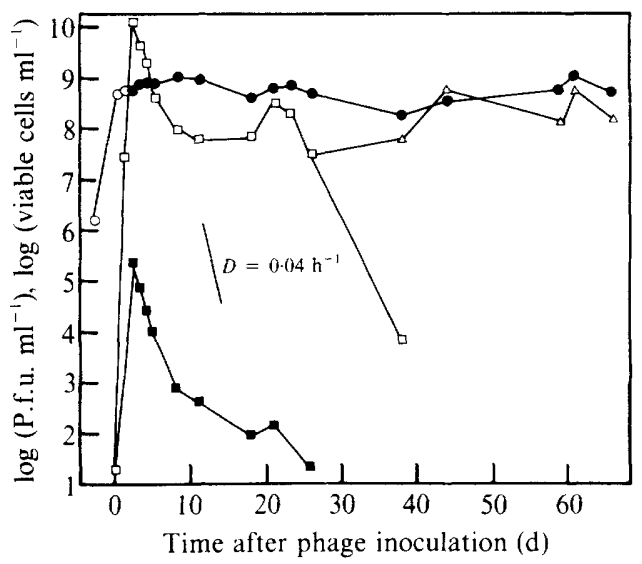

Fig. 2. Population dynamics in culture 2. $\bigcirc$, $\lambda$ vir-sensitive, Mal' bacteria;, mixed $\lambda$ vir-resistant and

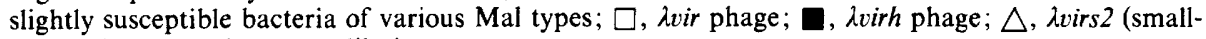
plaque-forming) phage; $D$, dilution rate.

\section{RESULTS}

\section{Population dynamics}

Fig. 1 shows the population dynamics in culture 1 in which $\lambda$ vir at a density of 20 p.f.u. $\mathrm{ml}^{-1}$ was introduced to a steady-state population of C600 bacteria at approximately $5 \times 10^{8}$ cells $\mathrm{ml}^{-1}$. The immediate epidemic growth of the phage at day 3 caused a decrease in the bacterial numbers. The bacteria recovered rapidly, at day 4 , becoming highly resistant to both the original and the co-occurring phage. After the evolution of resistance in the bacteria the phage declined until day 42 when a new phage type appeared which formed small plaques on original $\mathrm{C} 600$; this new population grew without reducing the dominant resistant bacterial population and by day 113 it appeared to have established equilibrium with its hosts. Phage and bacteria sampled at day 135 , at which time culture 1 was terminated, are referred to as selected strains and are designated as $\lambda$ virs 1 and $\mathrm{S}$, respectively.

The population dynamics in a repeat experiment (culture 2; Fig. 2) differed from those in culture 1 as follows: (i) the original sensitive bacteria were replaced by the resistant population, during the first peak of the phage, without any apparent drop in the total numbers; (ii) a second peak of the phage was observed at days 21-23 before the appearance of small-plaque-forming 
phage; (iii) the bacterial fluctuations were larger and suggested more intensive population interactions. In remarkable agreement with culture 1, however, small-plaque-forming phage appeared in culture 2 ( $\lambda$ virs 2 ) around day 40 . This phage was distinguishable by taking much longer to appear as plaques on assay plates. On the plates prepared for counting the phage sampled at day 38 the plaques of the original phage grew large and could easily be distinguished from the plaques of the new type, which started to appear only on the second day of incubation. The phage population shown in Fig. 2 as black squares is discussed later.

\section{Characterization of selected bacteria}

The properties of the selected bacteria are compared with those of the original bacteria in Table 1 . The presence of the $\mathrm{Thr}^{-}, \mathrm{Leu}^{-}$and $\mathrm{Thi}^{-}$markers, together with the ability to support the growth of coliphage $T_{4} r$, was determined in all selected strains characterized, to guard against the selection of contaminants. The chemostat population, 1 or 2 , from which the strains arose, is shown in Table 1, column 2.

Complete $\mathrm{Mal}^{+}$and $\mathrm{Mal}^{-}$phenotypes were found, being distinguished as black or colourless colonies, respectively, on EMBmal media. Additionally there was a wide range of intermediate Mal phenotypes which formed colourless colonies on EMBmall but developed full, or some, colour on EMBmallI. Polymorphism was also found in the size and texture of the colonies of the selected bacteria; some were small like the wild-type, some were large and showed spreading growth, and, on maltose-containing media, but not on LA, some were very mucoid. The colonies and the liquid cultures of all the selected types examined under the microscope always contained a number (about $10 \%$ ) of elongated or filamentous cells, whereas such cells were not found in cultures of original bacteria. Also, some isolates gave rise to stable mutants with altered colony morphology (S4, S5) or with reduced susceptibility to phage (S3, S4, S5) at exceptionally high frequencies (over 0.01 ) so that their single-colony subcultures were always polymorphic. In Table 1 the mutants of these isolates, which presumably coexisted with their parents in culture 1 , are designated with two- (secondary isolate) or three- (tertiary isolate) digit numbers. Not all primary isolates gave rise to the mutants indicated and the quantitative relationships of the types in the chemostat cultures were only partially determined.

Bacteria with some susceptibility to phage were found among intermediate Mal types whereas all the typical $\mathrm{Mal}^{+}$and $\mathrm{Mal}^{-}$isolates tested were totally resistant. Original bacteria were not found.

Mucoidity, a stable property of isolates S3, S4 and S51, can prevent phage attachment to receptor sites and therefore give rise to phenotypic resistance. However it appeared only on EMBmal media and was undetectable on LA, the solidified form of the culture medium. This does not preclude some effect in the cultures which might confer a selective advantage in the phage-rich environment, but this is thought to be unlikely.

One bacterial type, S3 from culture 1, coexisting with (and possibly host to) $\lambda v i r s$, was also susceptible to a host-range mutant of $\lambda$ vir (designated $\lambda v i r h$ from culture 2) but resistant to the original phage itself. Another type (the S4 and its mutants S41) was fully sensitive to all three phages. A third type (the S5 and its mutants S51) appeared resistant to all of the phages when grown on standard LA but became susceptible to all phages when maltose and phosphate were added to the medium. This change was assumed to be due to an induction of $\lambda$-receptor synthesis by the additives. Unlike the other resistant types, the $S 5$ bacteria allowed some growth of phage in liquid cultures even in the absence of maltose and phosphate, indicating that residual synthesis of $\lambda$-receptor was taking place under standard nutrient conditions. Similar susceptibility, though only to $\lambda$ virh and $\lambda$ virs 1 , was exhibited by a mutant of the S3 isolate (S313).

Table 2 shows the ability of the phages to adsorb onto original and selected bacteria. These experiments confirmed that, unlike the S5 bacteria, the S1 and the S2 types could not be induced by maltose and phosphate to produce functional $\lambda$-receptors. They also revealed that $\lambda v i r$ did adsorb irreversibly on S3 bacteria at a normal rate and, therefore, its development was impaired at a later stage. However, the host-range-enhanced mutant phages, $\lambda$ virh and $\lambda$ virs $I$, were both able to infect $\mathrm{S} 3$ cells and give rise to progeny viruses, although a proportion of infections were non-productive. 

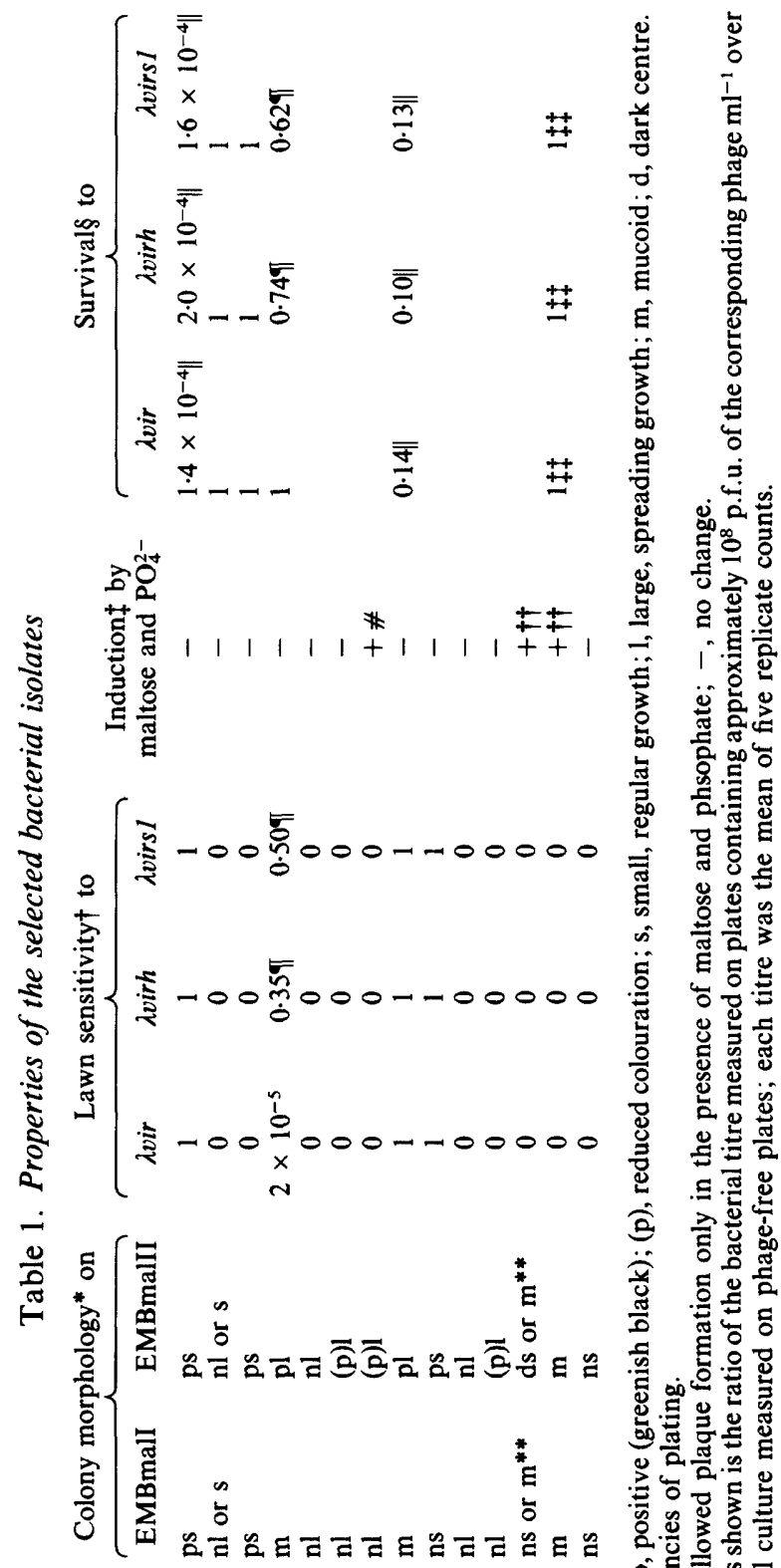

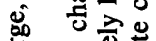

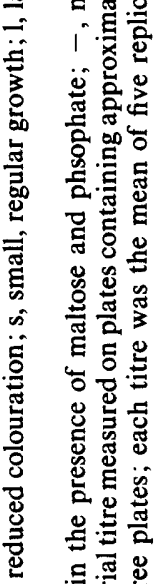

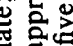

की.

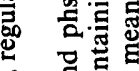

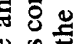

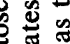

要要

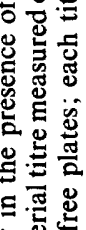

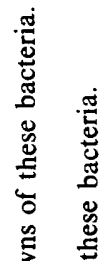

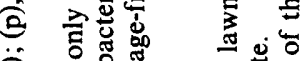

尊

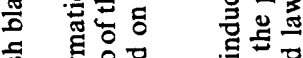

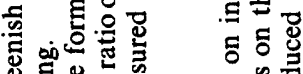

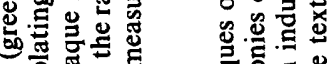

远总

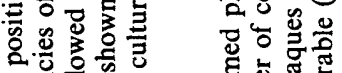

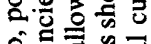

离要

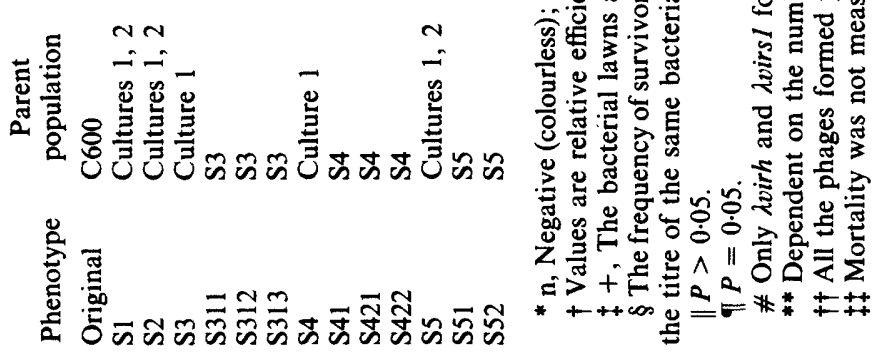


Table 2. Phage adsorption on selected bacteria

\begin{tabular}{lccc} 
& \multicolumn{3}{c}{ Phage adsorption* } \\
\cline { 2 - 4 } Bacteria & $\lambda$ vir & $\lambda$ virh & $\lambda$ virs I \\
Control & 76 & 45 & 94 \\
S1 & 0 & 0 & 0 \\
S2 & 0 & 0 & 0 \\
S3 & $75 \dagger$ & $77 \ddagger$ & $85 \S$ \\
S4 & 64 & 73 & 80 \\
S5 & 0 & 0 & 0 \\
S1 Induced $\|$ & 0 & 0 & 0 \\
S2 Induced & 0 & 0 & 0 \\
S5 Induced $\|$ & 92 & 92 & 96
\end{tabular}

\footnotetext{
* Values are percentages of the input phage titre found as infected cells at $15 \mathrm{~min}$ from mixing, and are the means of at least two replicate measurements; 0 indicates non-measurable adsorption.

$\dagger$ Adsorption was totally non-productive.

$\ddagger$ Only $71 \%$ of the total adsorption was productive.

$\S$ Only $75 \%$ of the total adsorption was productive.

|| Induction was by maltose and phosphate (see Methods).
}

An attempt was made to follow the dynamics of the above bacterial subpopulations in culture 2 in order to determine their quantitative importance in time. Several intermediate Mal types together with typical $\mathrm{Mal}^{-}$bacteria co-dominated the culture after the phage epidemic and remained at roughly equal frequencies until the end of the experiment. The overall resistance of this mixed population was of the $\mathrm{S} 5$ type but individual colony isolates which exhibited this type of resistance were somewhat rarer than the totally resistant ones. Typically $\mathrm{Mal}^{+}$bacteria or bacteria which were susceptible to the phages under standard growth conditions were not found in culture 2, while the extinction of the $\lambda v i r h$ population (shown in Fig. 2 with black squares) implied that S3 and S4 bacteria were also very infrequent or absent from this culture.

\section{Characterization of the selected phage}

גvirs I formed plaques on S3 bacterial lawns with a higher efficiency than $\lambda$ virh (Table 1), indicating that $\lambda$ virs 1 was a different, or, perhaps, a multiple $h$-mutant. $\lambda$ virs 2 differed in this respect from all other phages since neither was it an $h$-mutant itself nor did it produce $h$-mutants under the conditions of these chemostats. $\lambda$ virh formed normal plaques, confirming that the small-plaque phenotype exhibited by $\lambda$ virs 1 and $\lambda$ virs 2 was independent of the ability, or inability, of the phages to grow on $\mathrm{S} 3$ bacteria.

Comparing the kinetics of the adsorption of the original and the selected phage on the original bacteria it was found that selection had increased the affinity of the phage for its wild-type receptor. The adsorption-reaction constant, which is a measure of this affinity (Schwartz, 1976) was $5.25 \times 10^{-10} \mathrm{ml} \mathrm{cell}^{-1} \mathrm{~min}^{-1}$ for $\lambda$ virs 1 , compared with only $1.92 \times 10^{-10} \mathrm{ml} \mathrm{cell}^{-1} \mathrm{~min}^{-1}$ for $\lambda$ vir $(P \leqslant 0.001)$.

Although $\lambda$ virl was of the same serotype as $\lambda v i r$ (i.e. it was inactivated by $\lambda v i r$-specific antiserum) its antigen, probably the $\mathrm{J}$ terminal tail-fibre protein normally responsible for $h$ mutations, had altered during the course of selection in culture 1 . This was seen by comparing the rates at which the antiserum inactivated the two phages. The inactivation constant for $\lambda v i r s 1$ was only $256.65 \mathrm{~min}^{-1}$, compared with $527.36 \mathrm{~min}^{-1}$ for $\lambda$ vir $(P \leqslant 0.01)$. This serological difference is about as great as that between the coliphages T2 and T4 (Streisinger, 1956).

\section{Bacterial growth and competition in phage-free cultures}

The mean generation time of the selected bacteria growing exponentially was significantly longer than that of the original bacteria $(P \leqslant 0.05$; Table 3$)$. Two spontaneous $\lambda$-resistant mutants of the original bacterium were used as controls in this experiment; the mutations to $\lambda$ resistance carried by these strains did not affect their intrinsic growth rate. 


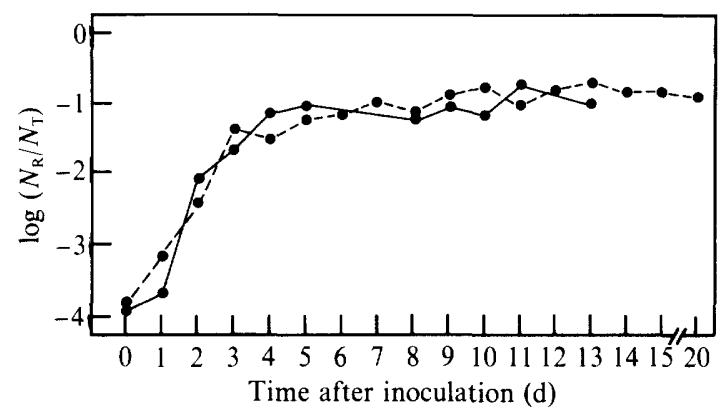

Fig. 3 Frequencies of $\lambda v i r$-resistant bacteria in control, phage-free, chemostats inoculated with $\lambda v i r-$ sensitive $\mathrm{C} 600$ bacteria alone. $N_{\mathrm{R}}$, Viable $\lambda$ vir-resistant cells $\mathrm{ml}^{-1} ; N_{\mathrm{T}}$, total viable cells $\mathrm{ml}^{-1}$. The solid and dotted lines represent two replicate experiments.

\section{Table 3. Intrinsic generation times of control and selected bacteria}

Values were estimated as $k^{-1}$ from equation (1) (see Methods). All strains showed an initial lag of approximately $1 \mathrm{~h}$. Confidence limits are at $P=0.05$ and with 6 degrees of freedom.

\begin{tabular}{|c|c|}
\hline $\begin{array}{l}\text { Bacterial } \\
\text { strain }\end{array}$ & $\begin{array}{c}\text { Generation time } \\
(\min )\end{array}$ \\
\hline C600 (control) & $28 \cdot 3 \pm 1 \cdot 1$ \\
\hline $\mathrm{C} 600 / \lambda$ & $27.3 \pm 1.0$ \\
\hline $\mathrm{C} 600 \mathrm{mal} / \lambda$ & $27 \cdot 6 \pm 1 \cdot 1$ \\
\hline S1 & $33.7 \pm 1.4$ \\
\hline S2 & $34.9 \pm 1.8$ \\
\hline S3 & $32.9 \pm 1.6$ \\
\hline S4 & $35.2 \pm 1.8$ \\
\hline S5 & $33 \cdot 3 \pm 1 \cdot 5$ \\
\hline
\end{tabular}

To test the ability of the original and the selected bacterial strains to compete in the absence of phage, three replicate chemostats (cultures 3 ) were inoculated with $1 \mathrm{ml}$ of equally dense cultures of original C600, S1, S2, S3, S4 and S5 bacteria and run for $15 \mathrm{~d}$ (approximately 21 generations). From day 4 onwards all three cultures were dominated by populations which appeared homogeneous $\mathrm{Mal}^{-}$on EMBmall but, as seen on EMBmalII, these consisted of several intermediate Mal types at about equal frequencies. The overall resistance of these populations was, as in culture 2, of the S5 type. During this time the original and the S1, S2, S3 and S4 bacteria were reduced to undetectable frequencies. This emphasizes that intrinsic exponential growth rate, measured in batch culture, is not indicative of 'fitness' in the chemostat environment.

In two replicate control chemostats (cultures 4), which were inoculated with original C600 bacteria alone, $\lambda$-resistant mutants increased in frequency (Fig. 3) although with no tendency to replace their parental $\lambda$-sensitive population. Interestingly, however, these resistant mutants were all typically $\mathrm{Mal}^{+}$even on EMBmalI.

\section{DISCUSSION}

The complexity of the bacterial populations after the addition of phage is greater than any previously reported (Barnet et al., 1981, mentioned similar complexity but gave no details). Although predominantly resistant, partially resistant bacterial subpopulations allow phage to persist indefinitely as predicted by Levin et al. (1977).

Host mutations causing reduced affinity of the original phage for the receptor resulted in the selection of mutant phage that could more efficiently infect the mutant hosts. Thus, in effect, the phage evolved progressively towards increased affinity for the receptor. The cause of the smallplaque phenotype, one of the most commonly reported changes in continuous cultures (Paynter 
\& Bungay, 1969, 1971; Horne, 1970a; Cowlishaw \& Mrsa, 1975; Chao et al., 1977) remains unclear. The phage may have adapted to the physiology of slowly growing bacteria, which is known to be different from that of rapidly growing bacteria (Milne et al., 1975; Nierlich, 1978), altering its ability to grow on 'young' bacterial lawns. Horne (1970a) proposed that the minute plaques, reflecting a very extended growth cycle, might be a consequence of selection in a system where very few suitably sensitive hosts were present with the consequent advantages of a prolonged residence time. The reduction of available receptor sites on bacteria of intermediate resistance, seen here, although different in detail from Horne's hypothesis, might create precisely similar selection pressures on the phage.

The variation between cultures intended to be replicates, as seen here between cultures 1 and 2 , has been reported by many other authors (see Introduction) and shown not to be due to sampling variations. Although, therefore, the present observations, especially the characterization of selected strains, extend our understanding of such systems, they also warn that a common explanation of the dynamics of phage-bacterial populations may be unwise. As the use of bacterial fermentation in industrial biosynthesis continues to expand it becomes increasingly important to understand these interactions, since phage contamination can cause much economic loss.

\section{REFERENCES}

ADAMS, M. H. (1959). Bacteriophages. New York, London \& Sydney: Interscience Publishers.

A PPLEYARD, R. K. (1954). Segregation of new lysogenic types during growth of a doubly lysogenic strain derived from E. coli K12. Genetics 39, 440452.

Barnet, Y. M., Daft, M. J. \& Stewart, W. D. P. (1981). Cyanobacteria-cyanophage interactions in continuous culture. Journal of Applied Bacteriology 51, 541-552.

CAMpbell, A. (1961). Conditions for the existence of bacteriophage. Evolution 15, 153-165.

Cannon, R. E., Shane, M. S. \& Whitaker, J. M. (1976). Interaction of Plectonema boryanum (Cyanophyceae) and the LPP cyanophages in continuous culture. Journal of Phycology 12, 418-421.

ChaO, L., Levin, B. R. \& Stewart, F. M. (1977). A complex community in a simple habitat: an experimental study with bacteria and phage. Ecology 58, 369-378.

Cowlishaw, J. \& Mrsa, M. (1975). Coevolution of a virus-alga system. Applied Microbiology 29, 234-239.

Davison, P. F. \& Freifelder, D. (1966). Liability of single-stranded deoxyribonucleic acid to hydrodynamic shear. Journal of Molecular Biology 16, 490-502.

HORNE, M. T. (1970a). Coadaptation in model ecosystems. PhD thesis, University of Wales.

HORNe, M. T. (1970b). Coevolution of Escherichia coli and bacteriophages in chemostat culture. Science 168, 992-993.

JaCOB, F. \& Wollman, E. L. (1954). Étude génétique d'un bactériophage tempère d'E. coli. I. Le système génétique du bactériophage. Annales de l'Institut Pasteur 88, 724-749.

Levin, B. R., Stewart, F. M. \& ChaO, L. (1977). Resource-limited growth, competition and preda- tion: a model and experimental studies with bacteria and bacteriophage. American Naturalist 111, 3-24.

Milne, A. W., Wai-Nam, M. \& Tze-Fei Wong, J. (1975). Variation of ribosomal proteins with bacterial growth rate. Journal of Bacteriology 122, 89-92.

Nierlich, D. P. (1978). Regulation of bacterial growth, RNA and protein synthesis. Annual Review of Microbiology 32, 393-432.

Paynter, M. J. B. \& BungaY, H. R. (1969). Dynamics of coliphage infections. In Fermentation Advances, pp. 323-335. Edited by D. Fertman. New York: Academic Press.

Paynter, M. J. B. \& Bungay, H. R. (1971). Characterization of virulent bacteriophage infections of Escherichia coli in continuous culture. With an answer by M. T. Horne. Science 172, 405 .

SCHLESINGER, M. (1932). Adsorption of bacteriophages to homologous bacteria. II. Quantitative investigation of adsorption velocity and saturation. Estimation of the particle size of the bacteriophage. Zeitschrift für Hygiene und Infectionskrankheiten 114, 149-160. [Translated in Papers on Bacterial Viruses, edited by G. Stent. Boston: Little, Brown \& Co.]

Schwartz, M. (1976). The adsorption of coliphage lambda to its host: effect of variation in the surface density of the receptor and in phage-receptor affinity. Journal of Molecular Biology 103, 521-536.

Streisinger, G. (1956). The genetic control of host range and serological specificity in bacteriophage $T_{2}$ and $\mathrm{T}_{4}$. Virology 2, 377-387.

SymondS, N. (1957). Effects of ultraviolet light during the second half of the latent period on bacteria infected with phage $\mathbf{T}_{2}$. Virology 3, 485-495.

Thirion, J. P. \& HofNung, M. (1972). On some genetic aspects of phage resistance in $E$. coli $\mathrm{K} 12$. Genetics 71, 207-216. 